\title{
A study for differences between different design drawing programs in sheet metal design
}

\author{
Yu-Che Huang ${ }^{1}$, Tien-Chaun Yeh $^{2}$ \\ ${ }^{1}$ Chaoyang University of Technology, Industrial Design Department, 168, Jifeng E. Rd., Wufeng Dist., Taichung 413, Taiwan (R.O.C.) \\ ${ }^{2}$ Chaoyang University of Technology, Industrial Design Department, 168, Jifeng E. Rd., Wufeng Dist., Taichung 413, Taiwan (R.O.C.)
}

\begin{abstract}
Most appearance and structure design has always been based on the product processing technology as the spindle, in general; sheet metal design changes in the appearance of the structure is based mainly on the basic structure of products and processing technology as the main core, and the appearance of manufacturing more Mechanical sheet metal, so most designers will use different design procedures to draw 3D graphics in the assembly or disassembly of parts, but different drawing procedures will affect the future assembly and disassembly of the design. In this study, we will compare two different models by building a model program using two different sheet metal structure drawings to present the problems that may be encountered in sheet metal design through a specific design flow. Through a real 3D drawing and design case, 3D graphics design flow, and finally through a design case to do a verification, to provide a reference for the future design.
\end{abstract}

\section{Introduction}

In the past, most mechanical sheet metal designs are based on the customer's design surface or 3D model as a design basis, and then through the R \& D department or designer for part assembly or 3D parts rebuild, and then to meet the processing Factory processing, and designer identification. In addition, if the same customer needs to reduce costs, the product must have a certain similarity, must be little change, often only a small number of holes or the main dimensions need to be modified, If you want to re-disassemble the parts or 3D surface redesign, it is easy to waste time, and the process is also prone to design errors, just as "At the present time CAD is not a suitable tool for engineers. a long training and a fulltime commitment are necessary to be proficient with the parametric history-based modeling technology[1,2,3].

Engineers need an easy-to-use 3D tool tailored for conceptual design but usually they communicate concepts through $2 \mathrm{D}$ sketching or presentation tools and then a $\mathrm{CAD}$ operator has to interpret their wishes in a specific modeling tool. This way is easy to commit errors and lose time often resulting in not substantially achieved engineer effectively wanted ". So how to provide a good way of drawing is a topic worth discussing..

\section{Literature}

In the past, the establishment of a model based on the traditional history-based model took a great deal of time and mental effort. At present, a highly competitive enterprise can no longer exist. Therefore, Computer
Aided Design (CAD) has been accompanied by computer operations since its introduction in the 1960s With the progress of capabilities and constant new developments, the model elements are modeled from the development of the wire architecture to the present, and from 2D to 3D in the space of the model. A new generation of modeling models (Direct modeling), also known as history-free model building, was first released by Space Claim Corporation in 2007, and then various vendors have also introduced the technology as The basic software[4,5,6,7], as shown in Table 2.

Among them, SIEMENS synchronous modeling technology introduced by Siemens in 2008 applied NX and Solid Edge software based on history-free direct modeling technology, providing designers with better design freedom. In addition, the software retains the traditional method of historical modeling, providing designers with the flexibility and choice to use. Combine it into two model building models. As shown in table 1:

Table 1. Different drawing methods.

\begin{tabular}{|c|c|c|}
\hline Drawing way & (History-Based) & (History-free) \\
\hline $\begin{array}{c}\text { Establish a model } \\
\text { approach } \\
\text { (Design method) }\end{array}$ & (Order modeling) & $\begin{array}{c}\text { (Synchronize } \\
\text { modeling })\end{array}$ \\
\hline
\end{tabular}


Table 2. Technical Development.

\begin{tabular}{|l|l|l|}
\hline Technology & Product & Main features \\
\hline $\begin{array}{l}\text { Synchronous } \\
\text { Technology }\end{array}$ & $\begin{array}{l}\text { Siemens NX } \\
\text { and } \\
\text { SolidEdge }\end{array}$ & $\begin{array}{l}\text { Hybrid technology: } \\
\text { the direct modeler } \\
\text { automate and control the } \\
\text { history tree }\end{array}$ \\
\hline $\begin{array}{l}\text { Inventor } \\
\text { Fusion } \\
\text { Technology }\end{array}$ & $\begin{array}{l}\text { Antodesk } \\
\text { Inventor } \\
\text { Cocreate }\end{array}$ & $\begin{array}{l}\text { Pybrid technology: is } \\
\text { parametric } \\
\text { and direct mode }\end{array}$ \\
\hline CoCreate & $\begin{array}{l}\text { Direct modeling with the } \\
\text { possibility to add } \\
\text { constraint } \\
\text { to the model }\end{array}$ \\
\hline SolidWorks & $\begin{array}{l}\text { Dassault } \\
\text { Systemes } \\
\text { SolidWorks }\end{array}$ & $\begin{array}{l}\text { Hybrid technology: direct } \\
\text { modeling features have } \\
\text { been gradually added in } \\
\text { SolidWorks }\end{array}$ \\
\hline $\begin{array}{l}\text { V6 direct } \\
\text { editing }\end{array}$ & $\begin{array}{l}\text { Dassault } \\
\text { Systemes }\end{array}$ & Hybrid technology \\
\hline SpaceClaim & SpaceClaim & Direct modeling \\
\hline Iron CAD & Iron CAD & Hybrid technology \\
\hline
\end{tabular}

\section{Research Methods}

This study attempts to explore several issues: 1 . HistoryBased modeling model and history-free model (HistoryFree) to establish a model approach in the design of sheet metal products are there any differences in the results of 2 . History-based approach (History-Based) to establish model and history-free (History-Free) the establishment of model methods in the design of sheet metal products efficiency is no difference between the time 3. HistoryBased model of the establishment of the history and history (History- Free). The establishment of model approach in the design of sheet metal products feel no difference.

In this study, Solid Edge ST8 is used as a tool to design the design process, hoping to find a faster and more suitable design method. Help R \& D or designers in the design of sheet metal applications. In addition, taking into account the operational limitations of the experiment, the choice of the electrical box as a case, are common sheet metal products, at the same time, in the experimental process to draw the model, the test will not cause too much difficulty.

\section{Reserch Result}

\subsection{Start sheet metal design}

In this part of the experiment, we want to explore the difference between synchronous modeling and order modeling when starting sheet metal design.

\subsubsection{Start sheet metal design in synchronous mode}

(Enter the part 1 to create the electrical box) Tools $\rightarrow$ Simultaneously build the model (Define the model used to build the model) (2) Center Point Rectangle $\rightarrow$ Smart Size $\rightarrow$ Stretch $\rightarrow$ Center Rectangle $\rightarrow$ Smart Size $\rightarrow$ Stretch Shell (To create the main body of the electrical box) (3) Center Point Rectangle $\rightarrow$ Smart Size $\rightarrow$ Mirror $\rightarrow$ Extrude $\rightarrow$ Center Rectangle $\rightarrow$ Smart Size $\rightarrow$ Mirror $\rightarrow$ Extrude $\rightarrow$ Linear $\rightarrow$ Smart Size $\rightarrow$ Mirror $\rightarrow$ Stretch (Excluding material) (Except for the model boundary to facilitate the follow-up model flat) (4) Center point and draw a circle $\rightarrow$ smart size $\rightarrow$ Stretch (Exclude) (after hole), 2D map of this study is shown in Figure 1 Show. Simultaneous establishment of model begin shown in Figure 1.

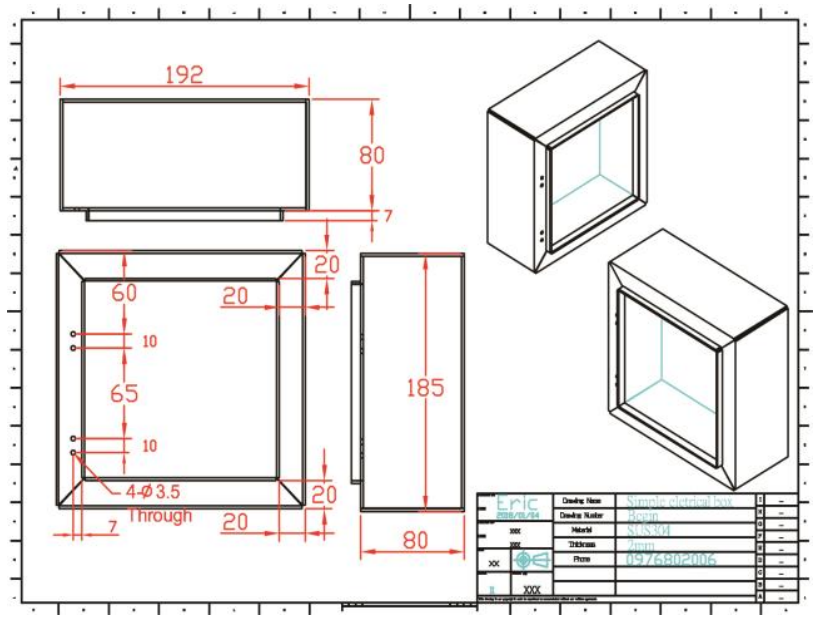

Figure 1. Begin drawings for simple electrical box.

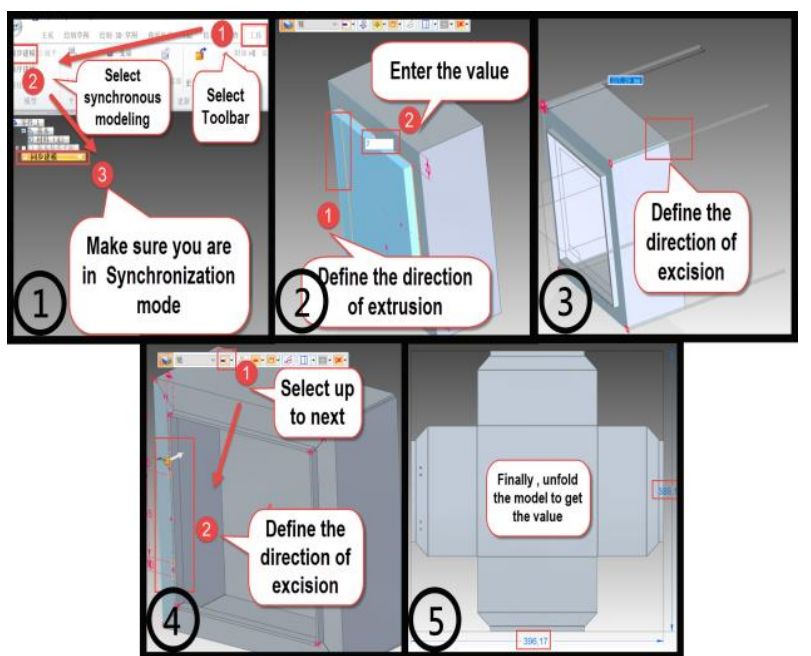

Figure 2. Synchronous mode to establish the model.

\subsubsection{Start sheet metal design in order mode}

Tools $\rightarrow$ Sequential Modeling (Define the model mode used) Sketch $\rightarrow$ Center Point Rectangle $\rightarrow$ Smart Size $\rightarrow$ Stretch $\rightarrow$ Sketch $\rightarrow$ Center Rectangle $\rightarrow$ Smart Size $\rightarrow$ Stretch $\rightarrow$ Thin Wall (Create Electrical Box Body) $\rightarrow$ Sketch $\rightarrow$ Center Point Rectangle $\rightarrow$ Smart Size $\rightarrow$ Mirror $\rightarrow$ Mirror $\rightarrow$ Stretch (Ext.) $\rightarrow$ Sketch Center Point Rectangle $\rightarrow$ Smart Size $\rightarrow$ Mirror $\rightarrow$ Mirror $\rightarrow$ Stretch (Ext.) $\rightarrow$ Sketch $\rightarrow$ Line $\rightarrow$ Smart Size $\rightarrow$ Mirror $\rightarrow$ Mirroring $\rightarrow$ Extrude (Excluding the model boundary for subsequent models) Basic drawing $\rightarrow$ Center point and 
Circle $\rightarrow$ Extrude (Create hole position behind), as shown in Figure 3.

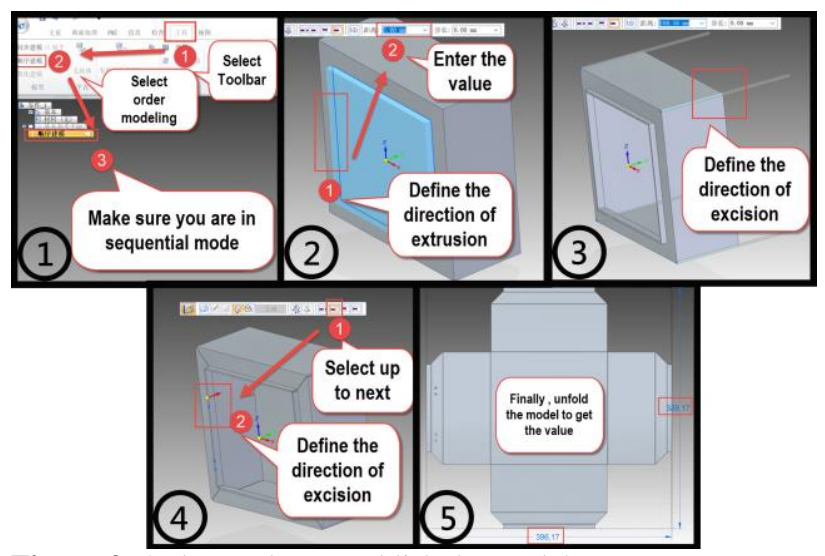

Figure 3. Order mode to establish the model.

\subsubsection{The difference between the two}

The simultaneous establishment of model and sequence model, the sheet metal design at the beginning of the construction, the instructions used in the difference is not too large, the most obvious difference is that the simultaneous model can be directly drawn in 3D space, and the order of the model Is the need to perform the drawing instructions, can sketch, in addition, the two finally expand the model, there is no difference in size, which means that both the model and the order of the establishment of the model to synchronize the two in the reconstruction of the sheet metal model, The final output of the model values and results no difference.

\subsection{Sheet metal design in design change}

In addition to the initial construction of the model in the sheet metal industry, design changes are also common issues in design. Therefore, it will be in the electrical box plate design changes in the site, and in different drawing patterns to compare the differences. The design changes in the site has the following 4 points:

(1) Electrical box length and width of the electrical box at the mouth(2)back hole diameter of the electrical box(3) Electrical box rear hole location(4)Electrical box height (plate thickness fixed).The following design changes when the sheet metal design reference map, as shown in Figure 4.

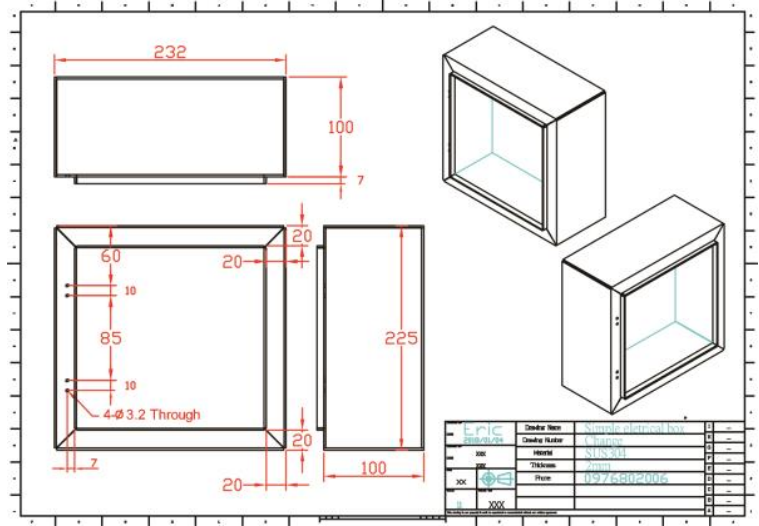

Figure 4. Design change drawings for simple electrical box.

\subsubsection{Design changes in synchronous mode in sheet metal design}

(1) select the function $\rightarrow$ modify the size $\rightarrow$ select the width of the frame part $\rightarrow$ modify the size.(2) Select four holes $\rightarrow$ modify the size. (3) Select the hole you want to move $\rightarrow$ Modify the size. (4) Select the upper part of the function keys $\rightarrow$ modify the size (this part of the instruction do not need to control).The relevant steps are shown in Figure 5.

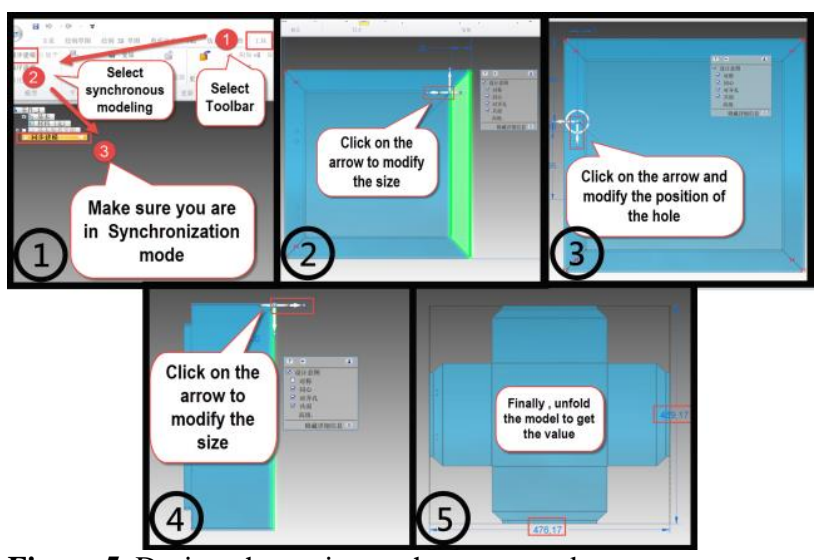

Figure 5. Design chages in synchronous mode.

\subsubsection{Design changes in order mode in sheet metal design}

(1) into the sketch $\rightarrow$ modify the size (length and width changes)(2) into the sketch $\rightarrow$ modify the size.(3) into the sketch $\rightarrow$ modify the size.(4) into the stretch $\rightarrow$ modify the size (high modify) (this part requires instructions to do control).The related steps are shown in Figure 6. 


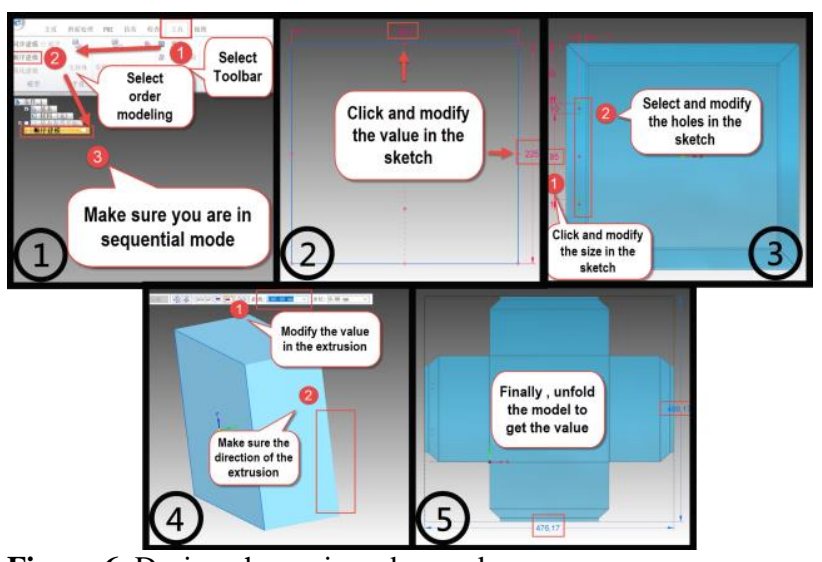

Figure 6. Design chages in order mode.

\subsubsection{The difference between the two design changes.}

Simultaneous modeling and sequential modeling, when the sheet metal design changes, synchronous modeling does not need to control through the instructions, and sequential modeling is based on the instruction back to the moon, to be modified, so if the order is built in the just When you start 3D rendering, there is no prior planning and future modifications can be a complex issue that can drastically reduce the designer's flexibility in designing. In addition, when both models are finally expanded, There is no difference in size, which means that both the synchronous model and the sequential model have no difference in the final design value of the sheet metal model. In designing, efficiency is the most important factor. In this study, the design process of Solid Edge ST8 was used as a planning tool. Subjects of industrial designers were tested and experimentally designed to give different subjects The modeling approach to the design process allowed the participants to draw the model based on pre-provided 2D maps and record the time it took. The test results are shown in the following Figure 7.

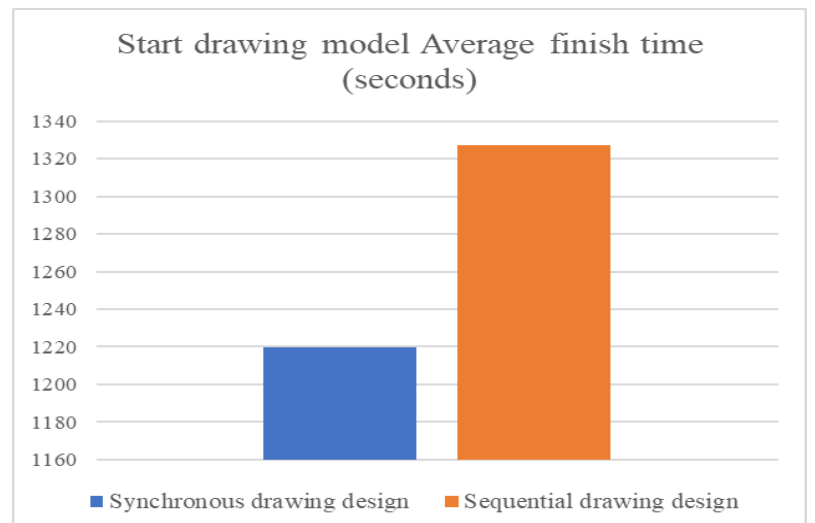

Figure 7. Start drawing model average finish time (seconds).

As you can see from the beginning of the design, the synchronous mode takes less time to complete, but the different result when the $3 \mathrm{D}$ design changes. The less time it takes for the sequential mode to be modeled, as shown in Figure 8.
In addition, a very time-consuming process of designing the work, the study used Solid Edge ST8 to plan the design flow. The experiment was conducted by the testers to draw 3D images and through two different design drawing methods Tests were designed to give participants different design approaches for modeling. Subjects were asked to draw $3 \mathrm{D}$ on the basis of the graphic content provided in this experiment. Then questionnaires were collected to collect the experience of the subjects using two different drawing and design methods. The test results are shown in Figure 8 below.

From the questionnaire of Figure 8 and related experimental results we can see that, whether it is in the beginning of the design or design changes, most of the subjects that synchronization modeling is easy to operate, the operation is also more efficient than sequential modeling, the other, The feeling of using it is also more relaxed.

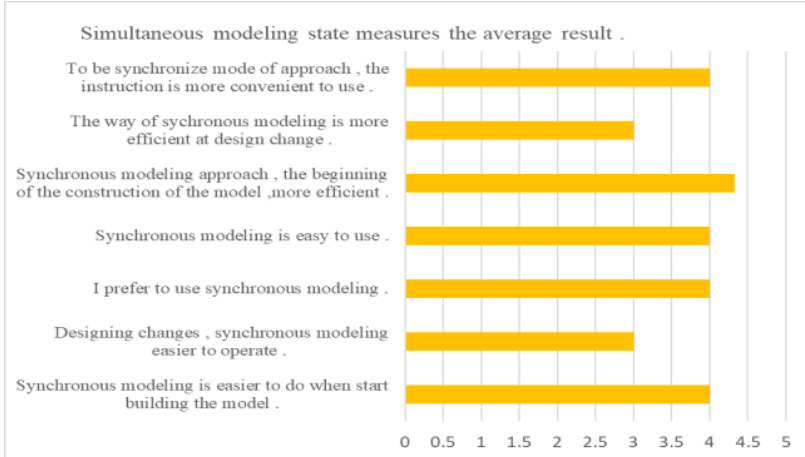

Figure 8. Simultaneous Modeling Attitude Scale Average.

\section{References}

1. Stefano Tornincasa, Francesco Di Monaco,The futureand the Evolution of CAD,Trends in the Development of Machinery and Associated Technology ,(2010)

2. Jenkins B. , 3D Engineering: How 3D Direct Modeling Empowers Conceptual Engineering and EnablesSimulation-Driven Product Development, White Paper,Ora Research LLC.( 2009)

3. Chang Meng-Liang, A Study of Key Success Factors on Operational Performance for Sheet Metals Industry in Central Taiwan, ( 2014)

4. Gordon L., Comparing 3D CAD modelers, machinedesign.com,(2006)(http://machinedesign.co $\mathrm{m} /$ article/comparing-3d-cad-modelers-1122)

5. Sunil V.B., Pande S.S., Automatic recognition of features from freeform surface CAD models, Computer-Aided Design 40, 4 (2008), 502-517.

6. Sunil V.B., Agarwal R., Pande S.S., An approach to recognize interacting features from B-Rep CAD models of prismatic machined parts using a hybrid (graph and rule based) technique, Computers in Industry(in press), 2010.

7. Fiorentino M., Uva A.E., Dellisanti Fabiano M., Monno G., Improving bi-manual 3D input in CAD modeling by part rotation optimisation, ComputerAided Design 42,5(2010), 462-470. 